В.П. Корніловський, Н.В. Головащенко

\title{
МАТЕМАТИЧНІ ХАРАКТЕРИСТИКИ БАГАТОКАНАЛЬНИХ ІНФОРМАЦЙНИХ СИСТЕМ З ШУМОПОДІБНО КОДОВАНИМИ СИГНАЛАМИ
}

\begin{abstract}
Вступ
\end{abstract}
Основним завданням при створенні систем передачі інформаціі є захист від різноманітного роду завад та викривлень. Завдання виявилося настільки тяжким, що багато ії аспектів не вирішено до цих пір. Для рзозв'язання цього завдання сформувався новий науковий напрямок, який здобув назву теорії інформації або теорії передачі сигналів. Було сенсацією, що ідеальним сигналом для передачі інформації, як довело відкриття К. Шеннона, виявляється шум. 3 формул беззаперечно поставало, що саме сигнал у формі шума виявляеться найбільш неочікуваним для одержувача і тому може бути найефективним для зв'язку.

Развиток телекомунікаційних засобів нової генерації заснований на заміні звичайних сигналів на більш складні сигнали, з введенням надмірності. Велике розповсюдження набуває використання широкосмугових сигналів з великою базою[1]:

$$
B_{c}=\Delta F \cdot T \gg 1
$$

Вони також мають назву шумоподібних. Використання в телекомунікаційних системах широкосмугових шумоподібних сигналів дозволяе підвищити завадостійкість, потаємність, та надійність передачі інформації при існуванні сильних завад та викривленнях у каналах зв'язку. Це є важливим фрактором при рішенні задачі, яка постає під час організації системи зв'язку на підприемствах в умовах сильних імпульсних завад та електромагнітного поля, від потужнього цехового електроустаткування. За рахунок розширення смуги частот несущих сигналів досягається збільшення швидкості передачі інформації, підвищуеться усталеність і надійність роботи радіоелектронних систем [2].

Часові діаграми, які пояснюють принцип утворення шумоподібно кодованих сигналів, зображені на рисунку 1.

Їх структура відображуе структуру квазівипадкових послідовностей $\left\{a_{i}\right\}_{\tau_{0}}^{T}$. В даному випадку:

$$
\left\{a_{i}\right\}_{\tau_{0}}^{T} \in 101101=x^{5}+x^{3}+x^{2}+1
$$

де $\tau_{0}$ - довжина елементарного кодового знака; $T$ - довжина послідовності.

Принцип формування полягае в тому, що “одиниці” коду повинні відповідати одній амплітуді (частоті, фазі), а "нулі” коду - іншій амплітуді (частоті, фразі). Таким чином можна сформулювати амплітудно-

(c) В.П. Корніловський, Н.В. Головащенко, 2004 


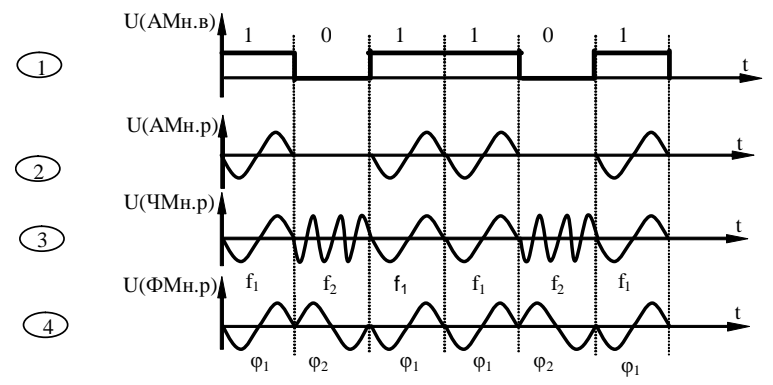

Рис. 1 - Часові діаграми шумоподібно кодованих сигналів

маніпульовані відеосигнали (АМн-відео, часова доріжка 1), амплітудноманіпульовані радіосигнали (АМн-радіо, часова доріжка 2), частотноманіпульовані радіосигнали (ЧМн-радіо, часова доріжка 3), фазоманіпульовані радіосигнали (ФМн-радіо, часова доріжка 4). Алгоритми формування можна описати таким чином:

для АМн-відео " 1 " $\rightarrow$ А відео, "0" $\rightarrow$ А відео $=0$;

для АМн-радіо "1" $\rightarrow$ А радіо, "0" $\rightarrow$ А радіо $=0$; (3)

для ЧМн-радіо “ 1 " $\rightarrow \mathrm{f}_{1}$, " 0 " $\rightarrow \mathrm{f}_{2}$;

для ФМн-радіо “1" $\rightarrow \quad \varphi_{1}$, "0" $\rightarrow \quad \varphi_{2}$.

Згідно з рис.1 математичні моделі зображених ШКС можна записати таким чином:

$$
\begin{gathered}
U(\boldsymbol{\Phi} M \boldsymbol{H})=A \sin \left[\omega_{0} t+\Theta t\right] \\
U(\boldsymbol{\Psi M} \boldsymbol{H})=A\left[\sin \omega_{01} t \cos \Theta t+A \sin \omega_{02} t \sin \Theta t\right] \\
U\left(A M M_{\text {padio }}\right)=A \sin \omega_{0} t \sin \Theta t \\
U\left(A M M_{\text {iideo }}\right)=A \sin \Theta t
\end{gathered}
$$

де А - амплітуда сигнала; $\omega_{0}, \omega_{01}, \omega_{02}$ - частоти; $\Theta(t)=\pi\left\{a_{i}\right\}_{\tau_{0}}^{T}$.

При моделюванні генератора шумоподібно кодованих сигналів за допомогою пакета прикладних програм Electronics Workbench були здобуті наступні види сигналів, які зображені на рисунку 4 а) амплітудноманіпульований сигнал; б) частотно-маніпульований сигнал, в) фазоманіпульований сигнал.[3]

Найбільш загальну уяву про властивості сигналу дає автокореляційна фрункція комплексної амплітуди сигналу:

$$
B_{a}(\tau, \omega)=\left|\int_{-\infty}^{+\infty} \overrightarrow{U_{m}}(t) \overrightarrow{U_{m}^{*}}(t-\tau) e^{j \omega t} d t\right| \text { (5) де } \overrightarrow{U_{m}}(t) \text { - комплексна амплі- }
$$

туда сигналу, $\overrightarrow{U_{m}^{*}}(t)$ - комплексно-сполучена амплітуда сигналу, щ,ф часове і частотне зрушення.

Відмінною рисою шумоподібно кодованих сигналів е вигляд їх автокореляційної функції, яка подібна до автокореляційної функції шума: 
a)
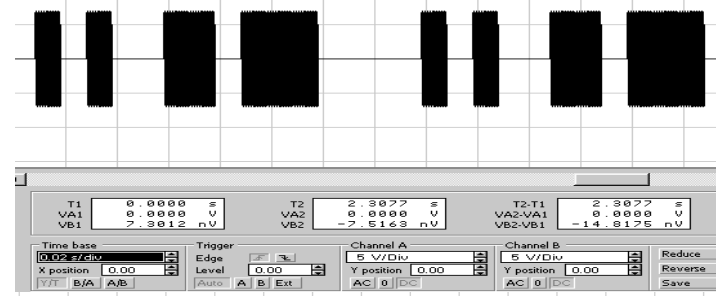

б)
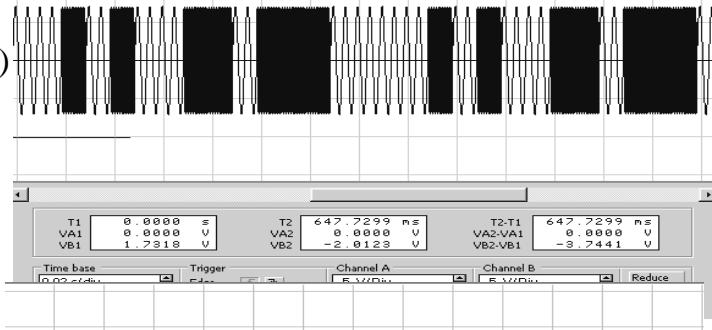

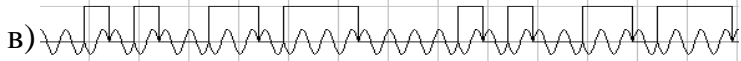

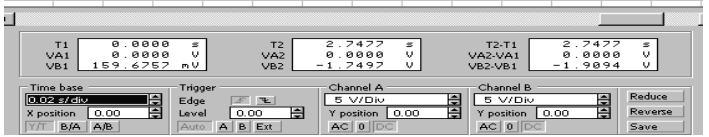

Рис. 2 - а) АМн-сигнал; б) ЧМн-сигнал; в) ФМн-сигнал 
вона має один вузький, у порівнянні із загальною довжиною сигнала, центральний пік та значно меньші за амплітудою бічні викиди. Якщо ми маємо меандр шумоподібно кодованого сигнала (рисунок 3), то отримаємо автокореляційну функцію, яка зображена на рисунку 4:

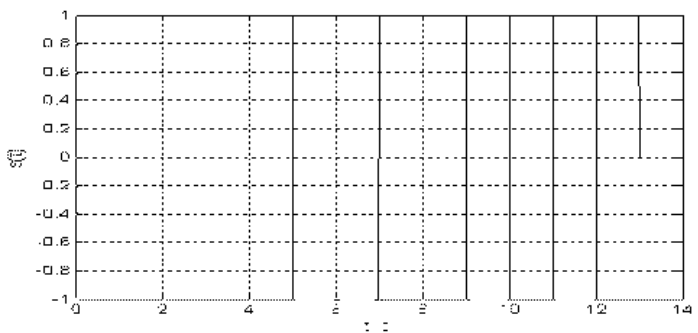

Рис. 3 - Фазоманіпульований шумоподібний сигнал

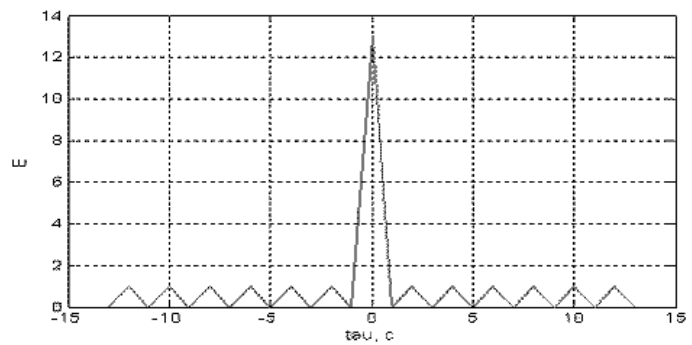

Рис. 4 - Автокореляційна фрункція фразоманіпульованого шумоподібного сигнала

Як бачимо з рисунка 4, амплітуда центрального викида автокореляційної функції $B_{a}(\tau, \omega)$ прямо-пропорційна довжені сигнала. Часовий інтервал кореляції зворотньо-пропорційний смузі частот сигнала. Таким чином $B_{a}(\tau, \omega)$ дає змогу говорити про потенційну завадостійкість та розподільчу спроможність за часом,які забезпечуються сигналом. У випадку, якщо взаємокореляційні функції сигналів $B_{6 з}(\tau, \omega) \cong 0$, тобто, не мають яскраво виражених піків, а невеликі викиди розподілені по вісі часу, то $B_{63}(\tau, \omega)$ є еквівалентом ортогональності сигналів. Для ортогональних сигналів $S_{1}(t)$ та $S_{2}(t)$ має виконуватися умова:

$$
\overline{S_{1}(t) \cdot S_{2}(t)}=0
$$

Тобто, осереднений добуток двох сигналів $S_{1}(t)$ та $S_{2}(t)$ дорівнює нулю. Така властивість сигналів необхідна при побудові багатоканальних систем передачі інформації. Таким чином, фрункції $B_{b 3}(\tau, \omega)$ та $B_{a}(\tau, \omega)$ дозволяють вирішувати питання про перспективність сигналів для створення багатоканальних систем приймання-передачі. 
При організації багатоканальних інформаційних систем необхідно уживати ущільнення каналів на передаючому боці та розділення каналів на принімаючому боці. Розділення та ущільнення каналів можна учинити за частотою, часом та кодом.У нинішній час найбільше розповсюдження здобули системи які будувалися з використанням технологій з розділенням загального канала за кодом.

Принцип кодового розділення каналів зв'язку побудований на використанні широкосмугових сигналів (ШСС), смуга яких значно перевищуе смугу частот, необхідну для звичайної передачі повідомлень, наприклад у вузькосмугових системах з частотним розділенням каналів. Тобто кодове разділення базуеться на використанні шумоподібних сигналів. Расширення спектра частот передаваємих цифрових повідомлень може відбуватися двома методами або їх комбінацією:

1. пряме розширення спектра частот;

2. скачкообразною зміною частоти несущої.

При першому способі вузькосмуговий сигнал (рисунок 5) перемножуеться із псевдовипадковою послідовністю (ПВП) с періодом повторення Т, яка містить $\mathrm{N}$ біт послідовностей довжиною to кожний. В цьому випадку база ШСС численно дорівнює кількості елементів ПВП В-Т/to = N [2]

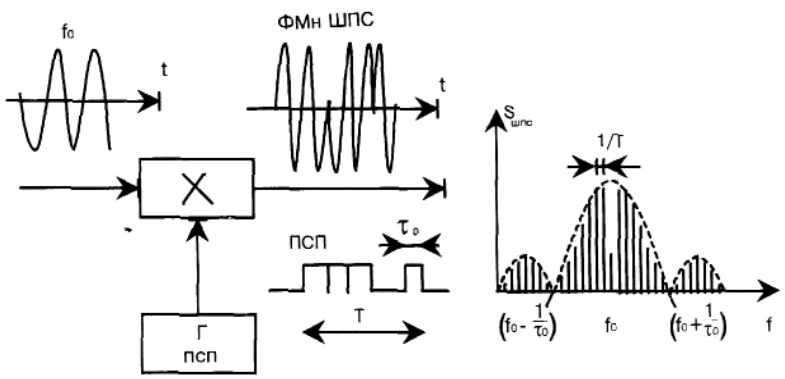

Рис. 5 - Пряме розширення спектра частот

Скачкообразна зміна частоти несущої (рис. 6), як правило, відбувається за рахунок швидкої перенастройки вихідної частоти синтезатора у відповідності із законом формування псевдовипадкових послідовностей.

Але переваги складних сигналів реалізовуються тільки у випадку узгодженого прийома. Завдання пошуку оптимального метода прийома зводиться до визначення такої імпульсної реакції $h(t)$ приймача, при якій досягаетьсямаксимальне перевищення сигналу над перешкодою на виході приймача. Відомо,що :

$$
\left.\begin{array}{c}
h(t)=\frac{1}{2 \pi} \int_{-\infty}^{+\infty} H(\omega) e^{j w t} d \omega \\
H(\omega)=\int_{-\infty}^{+\infty} h(t) e^{-j \omega t} d t
\end{array}\right\}
$$




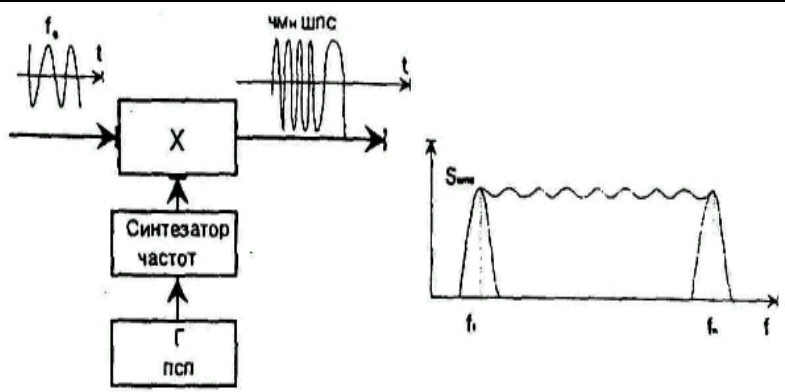

Рис. 6 - Розширення спектра частот скачкообразною зміною частоти несущої

Тому замість імпульсної реакції приймача можна визначити оптимальну частотную характеристику приймача $H(\omega)$, яка прийме вигляд:

$$
H(\omega)=a S^{*}(\omega) e^{-j \omega \tau}
$$

де $S^{*}(\omega)$ - функція, комплексноспряжена зі спектром сигналу, $\tau$ - час, а - довільна комплексна константатанта.

Формула (3) визначає потенційнй можливості сигналу, а фоормула (5) показуе яким має бути приймач.

Приймач, який є узгодженим зі спектром радіосигнала, називають оптимальним, тому що він забезпечує максимально можливе співвідношення сигнал/перешкода на виході $p_{\max }$ :

$$
p_{\max }=\frac{2 E}{N_{0}}
$$

де $E$ - енергія сигнала, $N_{0}$ - спектральная плотність завади на виході приймача, яка ураховуеться у вигляди гауссвого шума.

Приймання ШСС здійснюеться оптимальним приймачем, який для сигналу з повністтю відомими параметрами вираховує кореляційну функцію.

$$
z=\int_{0}^{T} x(t) u(t) d t
$$

де $x(t)$ - вхідний сигнал, який являе собою суму користного сигнала $u(t)$ та завади $n(t)$ (в данному випадку білий шум). Потім величина $\mathrm{Z}$ порівнюеться із порогом zq. Значення кореляційного інтеграла знаходиться за допомогою корелятора. (Рисунок 7) або узгодженного фільтра..

Корелятор здійснюе "стиснення" спектра широкосмугового вхідного сигнала шляхом помноження його на еталонну копію $u(t)$ із послідуючою фрільтрацією у смузі $1 / T$, що й призводитьдо покращення співвідношенн сигнал/завада на виході корелятора у В разів по відношенню входа. При 


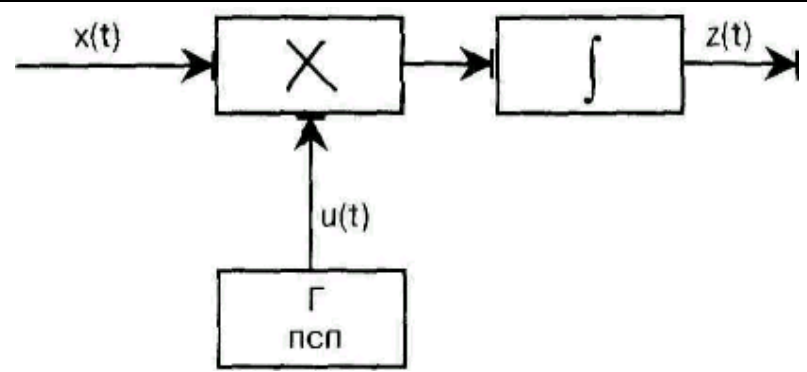

Рис. 7 - Корелятор

виникненні затримки між прийнятим та опорним сигналами амплітуда вихідного сигналу корелятора зменшуеться та наближається до нуля, коли затримка становить довжину елемента ПВП. Ця зміна амплітуди вихідного сигнала корелятора визначається видом АКФ - автокореляційної функції (якщо співпадають вхідний та опорний ПВП) та ВКФ - взаємокореляційної функції (якщо вхідна і опорна ПВП відрізняються).[4]

Поряд зі звичайними кореляційними функціями широко використовують знакові кореляційні функції. Їх розрахунок потребуе меньших затрат. Технічні спрощення при автоматичному розрахунку знакових кореляційних функцій досягаються завдяки тому, що процеси які досліджуються (один або обидва з кожної порівнюваної пари процесів) замінюють їх знаками /полярностями/. 3 ціїю метою використовуеться функція Sgn $\mathrm{x}$ - сігнум (знак) $\mathrm{x}$, яка обумовленна рівнянням:

$$
S g n_{x}=\left\{\begin{array}{c}
-1_{s} \kappa щ_{o}<0 \\
0_{s} \kappa о_{x}=0 \\
1_{s} \kappa о_{s} o_{x}>0
\end{array}\right.
$$

Тоді знакова взаємокореляційна функція випадкових процесів X та Y:

$$
\iota_{X Y}(\tau)=M[\operatorname{Sgn} \stackrel{0}{X}(t) \operatorname{Sgn} \stackrel{0}{Y}(t-\tau)]
$$

у випадку, коли $\mathrm{X}=\mathrm{Y}$ маємо вираз для знакової автокореляційної функції:

$$
\iota_{X}(\tau)=M[\operatorname{Sgn} \stackrel{0}{X}(t) \operatorname{Sgn} \stackrel{0}{X}(t-\tau)]
$$

При моделюванні цифрового корелятора [5] за допомогою прикладного пакета програм Electronics Workbench на виході корелятора була здобута автокореляційна фрункція, яка зображена на рисунку 8.

\section{Заключення}

Застосування широкосмугових шумоподібних сигналів забезпечує високу пропускну спроможність каналів, дозволяе ослабити вплив багатьох різновидів завад, а також бореться із впливом багатопроміневого 


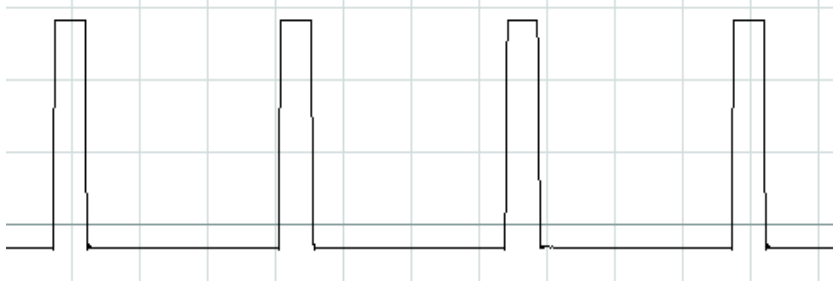

Рис. 8 - Автокореляційна фрункція шумоподібно кодованих сигналів

розповсюдження радіохвиль. Важливою особливісттю широкосмугових систем є добре електромагнітне сполучення з іншими радіоелектронними засобами за рахунок передавання у ефрір безперервних у часі шумоподібних сигналів з дуже низькою спектральною щільністю. А кореляційні функції шумоподібно кодованих сигналів дозволяють судити про потенційну завадостійкість системи, яка забезпечуеться сигналом, та про розподільчу спроможність сигналів за часом що є дуже важливим для синхронізації системи.

\section{Література}

1. Габидулин Э.М., Афранасьев В.Б. Кодирование в радиоэлектронике.М.: Радио и связь, 1986.

2. Варакин Л.Е. Системы связи с щумоподобными сигналами.- М.: Радио и связь 1985, 1985.-384C

3. Методичні вказівки для виконання лабораторних робіт з дисціпліни “Цифрова електроніка та ЕОМ в системах управління" для магістрів спеціальності 8.091.401 “Системи управління і автоматики”. /Корніловський В.П., Корніловська Н.В., Головащенко Н.В.-Херсон, ХДТУ, 2003, с 19,Укр.мовою.

4. Смирнов Н.И. Проектирование микроэлектронных устройств обработки шумоподобных сигналов. Часть 1 . Корреляционные свойства ШПС. Учебное пособие. М.:МЭИС. 1988.

5. Головащенко Н.В., Боярчук В.П. Аппаратурный состав для улучшения свойств трактов приёма-передачи информации в системах промышленной автоматики. - ААЭКС 1 (8) Херсон - 2003. - с.58-61 